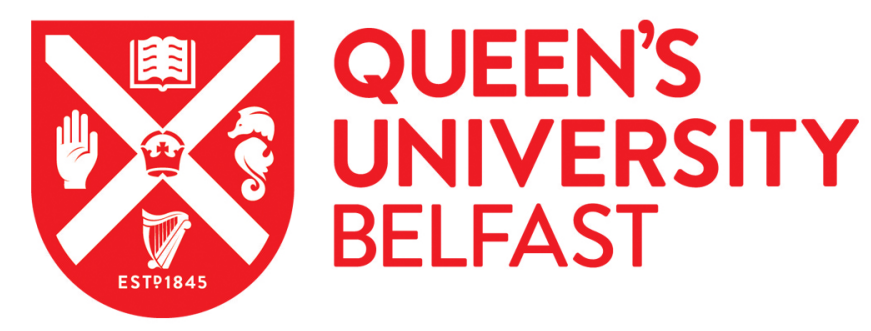

\title{
Controlling the materials properties and nanostructure of a single- component dendritic gel by adding a second component
}

Hardy, J. G., Hirst, A. R., Smith, D. K., Brennan, C., \& Ashworth, I. (2005). Controlling the materials properties and nanostructure of a single-component dendritic gel by adding a second component. Chemical Communications, (3), 385-387. https://doi.org/10.1039/b413629b

Published in:

Chemical Communications

Document Version:

Peer reviewed version

Queen's University Belfast - Research Portal:

Link to publication record in Queen's University Belfast Research Portal

Publisher rights

Copyright 2004 Royal Society of Chemistry

\section{General rights}

Copyright for the publications made accessible via the Queen's University Belfast Research Portal is retained by the author(s) and / or other copyright owners and it is a condition of accessing these publications that users recognise and abide by the legal requirements associated with these rights.

Take down policy

The Research Portal is Queen's institutional repository that provides access to Queen's research output. Every effort has been made to ensure that content in the Research Portal does not infringe any person's rights, or applicable UK laws. If you discover content in the Research Portal that you believe breaches copyright or violates any law, please contact openaccess@qub.ac.uk. 


\title{
Controlling the materials properties and nanostructure of a single- component dendritic gel by adding a second component
}

\author{
John G. Hardy, ${ }^{a}$ Andrew R. Hirst, ${ }^{a}$ David K. Smith, ${ }^{* a}$ Colin Brennan ${ }^{b}$ and Ian Ashworth ${ }^{b}$ \\ ${ }^{a}$ Department of Chemistry, University of York, Heslington, York, YO10 5DD, UK; \\ E-mail:dks3@york.ac.uk \\ ${ }^{b}$ Syngenta, Technology and Projects, Huddersfield, HD2 1FF, UK
}

This submission was created using the RSC ChemComm Template (DO NOT DELETE THIS TEXT)

(LINE INCLUDED FOR SPACING ONLY - DO NOT DELETE THIS TEXT)

This paper reports a dendritic system which is capable of forming both one-component and two-component gels interestingly the addition of the second component can either decrease or increase the degree of gelation, depending on dendritic generation.

The challenge of controlling multiple non-covalent interactions over nanoscopic distances has made the development of gelphase self-assembling systems one of the most exciting frontiers of supramolecular chemistry. ${ }^{1}$ Dendrimers are particularly interesting candidates for the gelation of organic solvents as they possess many repeating functional groups within their branched architectures. $^{2}$ These groups must be conformationally organised, and capable of interacting in an optimal fashion. Multi-component gelation systems are also of considerable interest. In such systems, several distinct molecules initially assemble into a complex, which then assembles further and forms one-dimensional aggregates with gel-phase properties. ${ }^{3}$ We have recently reported a two-component gelation system which employs dendritic building blocks and have extensively studied the ability of molecular-scale structural features to control the assembly process. ${ }^{4}$

In this new paper, we extend the concept of our original twocomponent gelation system. By changing the 'surface groups' on the dendron from Boc protecting groups to long alkyl tails, we generate a dendron which is, in its own right, a onecomponent gelator. In fact, peptidic molecules with long alkyl tails are well-known to promote gelation as a consequence of their preference for solvophobic packing and their ability to form van der Waals interactions. ${ }^{5}$ However, it has not previously been realised that such systems can also form a two-component complex on the addition of aliphatic diamine. Interestingly, the two-component system has different gel-phase materials properties to the dendron alone and furthermore, these differences are dendritically controlled.

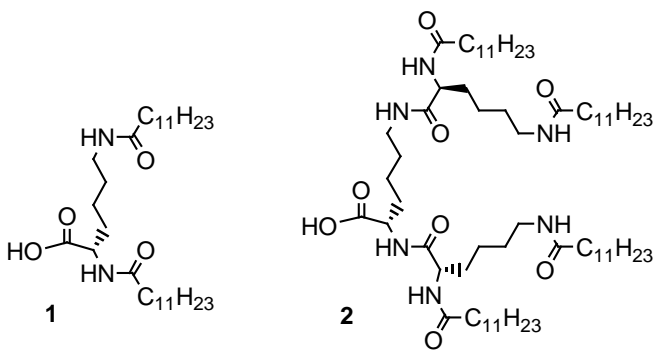

Figure 1. First (1) and second (2) generation dendrons.

The first and second generation dendrons functionalised with alkyl tails (1 and $\mathbf{2}$ respectively - Figure 1) were synthesised using a standard divergent strategy in which the previously reported ${ }^{4}$ Boc protected dendrons were deprotected using $\mathrm{HCl}$, converted to the free base amines, and subsequently coupled with dodecanoic acid using straight-forward DCC/HOBt peptide coupling methodology. Compound $\mathbf{1}$ has been previously investigated by Hanabusa and co-workers as a gelator. ${ }^{5 \mathrm{e}}$
The ability of dendrons $\mathbf{1}$ and $\mathbf{2}$ to form gel-phase materials in toluene was investigated using a heat-cool cycle and simple tube-inversion methodology. The concentration dependence of the $T_{\text {gel }}$ value (the temperature of the gel-sol phase boundary) is illustrated (Figure 3a). Dendron 2 formed effective gel-phase materials, with the $T_{\text {gel }}$ value increasing up to a 'plateau value' of ca. $87^{\circ} \mathrm{C}$ with increasing concentration of 2 . Dendron 1 , on the other hand, only formed very soft, weak, networks, with the $T_{\text {gel }}$ values remaining at approximately $20^{\circ} \mathrm{C}$ irrespective of concentration. This indicates that the additional dendritic branching of dendron 2 significantly assists in the assembly of gel-phase materials - presumably by allowing the formation of additional favourable non-covalent interactions. ${ }^{6}$

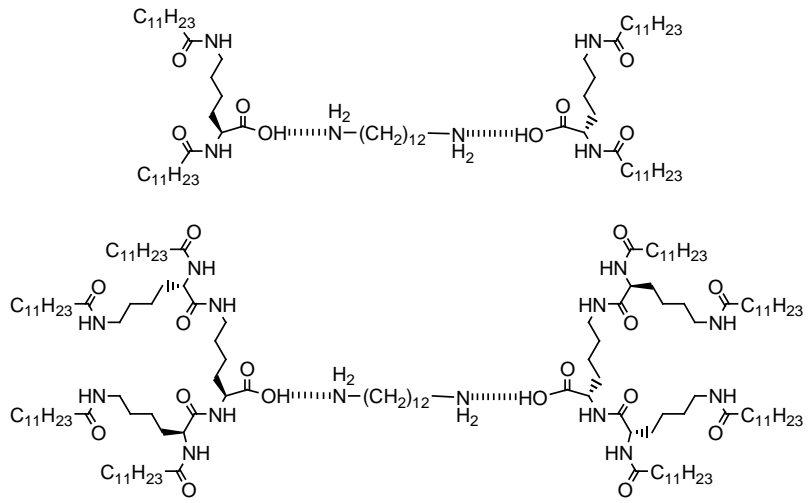

Figure 2. Two component gelation systems based on dendrons $\mathbf{1}$ and $\mathbf{2}$.
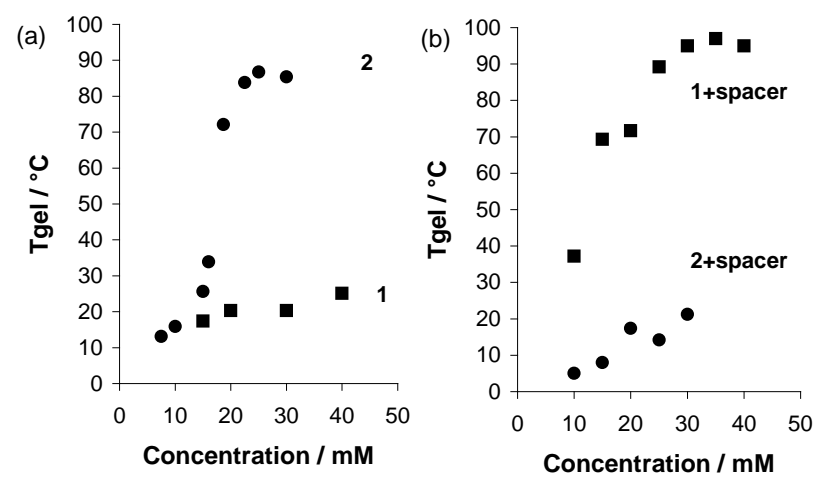

Figure 3. Concentration dependence of the thermal properties of gelphase materials formed using dendrons 1 and $\mathbf{2}$ (a) in the absence and (b) in the presence of diaminododecance spacer. All materials investigated had a 2:1 ratio of dendron to spacer chain in toluene.

The ability of dendrons $\mathbf{1}$ and $\mathbf{2}$ to form gel-phase materials was then investigated in the presence of diaminododecane after a heat-cool cycle. Figure 3b illustrates the thermal behaviour of the resultant two-component materials. On mixing dendron 1 (a poor gelator) with diaminododecane, a very effective gel was formed, and increasing the concentration of the gelator complex yielded a material with a $T_{\text {gel }}$ value of ca. $95^{\circ} \mathrm{C}$. In contrast, 
dendron 2 (a potent gelator) only formed very weak gels in the presence of diaminododecane, with a maximum $T_{\text {gel }}$ value of ca. $20^{\circ} \mathrm{C}$. The addition of the second-component therefore enhances the gelation process for dendron $\mathbf{1}$, but hinders the gelation process for dendron 2 . The gel-phase materials properties of the dendrons respond in opposite ways to the presence of a diamine additive. The dendritic control and supramolecular control of the gelation event appear to be orthogonal to one another.

In an attempt to shed further light on this process, the materials were imaged using scanning electron microscopy (SEM). SEM is a useful comparative technique for investigating dried samples of gel-phase materials. Dendron 1 proved amenable to SEM, and in the absence of diaminododecane gave the image in Figure 4a, whilst in the presence of the spacer chain gave the image in Figure $4 \mathrm{~b}$. It is clear that the addition of the second-component dramatically changes the nanoscale-morphology of the assembled superstructure. On its own, dendron 1 forms flattened tapes ca. 1-3 $\mu \mathrm{m}$ in width. Similar structures have sometimes previously been visualised for peptidic molecules functionalised with hydrophobic tails. ${ }^{5}$ However, in the presence of the second component, the network appears to interpenetrate more and consists of narrower nanoscale fibres. Qualitatively, it would be expected that the more interpenetrated network, which has more 'connecting points', should form a better gel, and this is in agreement with the $T_{\text {gel }}$ values discussed above. In the absence of the spacer, the structure formed by dendron $\mathbf{1}$ appears to be more rigid and ordered, and it is interesting to speculate that this structure has a higher degree of crystallinity.

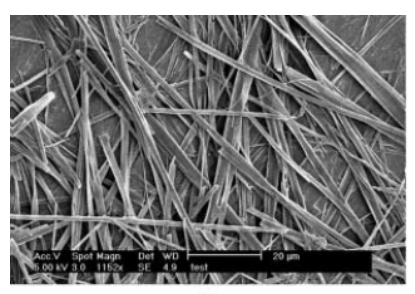

(a)

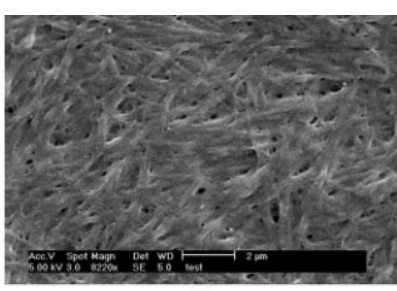

(b)
Figure 4. SEM images of dendron 1 in the absence (a, scale bar $=20$ $\mu \mathrm{m})$ and the presence (b, scale bar $=2 \mu \mathrm{m})$ of diaminododecane.

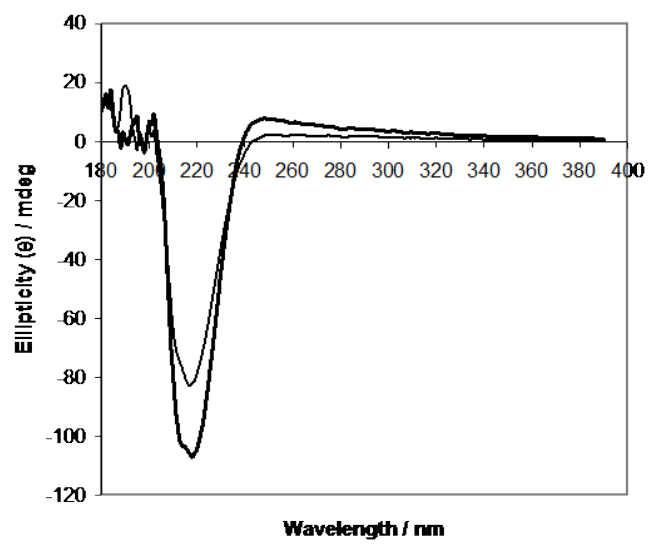

Figure 5. CD spectra of dendron 2 (3 mM) in the absence (bold) and the presence (light) of diaminododecane $(1.5 \mathrm{mM})$.

Unfortunately, it was not possible to obtain SEM images of the materials based on dendron $2 .^{7}$ Circular dichroism (CD) experiments were therefore performed in order to further study the nanoscale ordering of these gel-phase materials. It is wellknown that a CD signal results from the ordering of chiral building blocks on the nanoscale. Dendron $2(3.0 \mathrm{mM})$ was investigated in cyclohexane (optically transparent at the relevant wavelength) both in the absence and in the presence of diaminododecane $(1.5 \mathrm{mM}) .{ }^{8}$ In both cases, a signal at ca. 220 nm was observed, consistent with anisotropic organisation of the $\mathrm{CONH}$ groups within the dendron via dendron-dendron hydrogen bonds (Figure 5). Interestingly, dendron 2 alone exhibited a larger signal $(\theta=-107$ mdeg) than it did in the presence of diaminododecane $(\theta=-83 \mathrm{meg})$. Furthermore, the Cotton effect was more pronounced when the diamine was not present. These observations are consistent with the fact that adding diaminododecane inhibits the ability of dendron 2 to act as an effective gelator, indicating that diaminododecane limits the assembly and chiral organisation of dendron $\mathbf{2}$ on the nanoscale. It is proposed that dendron $\mathbf{2}$ can assemble effectively on its own into nanoscale structures, perhaps as a consequence of acid-acid interactions and van der Waals interactions between the alkyl tails. ${ }^{2 \mathrm{~d}}$ However, on the addition of the aliphatic diamine, acid-acid interactions are replaced by acid-base interactions, and the resultant two-component complex is less able to organise itself effectively on the nanoscale.

In summary, this paper reports first and second generation dendrons, the gel-phase materials properties of which respond in opposite ways to the presence of a diamine additive. This is a remarkable example in which dendritic generation and the use of a second (supramolecular) component can both control materials properties. This can be considered as orthogonal dendritic control and supramolecular control. In the future, materials switchability may be built into gelation systems by designing-in the ability for them to interact specifically with a second component which can either enhance or inhibit gelation in this way. We are currently in the process of investigating this unique system further, in order to determine the reasons for the orthogonal control mechanisms, as well as developing other new switchable and controllable gel-phase materials.

\section{Notes and references}

1 (a) P. Terech and R. G. Weiss, Chem. Rev. 1997, 97, 3133-3159. (b) O. Gronwald E. Snip and S. Shinkai, Curr. Opin. Coll. Interface Sci. 2002, 7, 148-156. (c) L. A. Estroff and A. D. Hamilton, Chem. Rev. 2004, 104, 1201-1217.

2 (a) W. D. Jang and T. Aida, Macromolecules 2002, 35, 9015-9021. (b) W. Zhang, S. O. Gonzalez and E. E. Simanek, Macromolecules 2002, 35, 9015-9021. (c) E. R. Zubarev, M. U. Pralle and S. I. Stupp, J. Am. Chem. Soc. 2001, 123, 4105-4106. (d) C. Kim, K. T. Kim, Y. Chang, H. H. Song, T. Y. Cho and H. J. Jeon, J. Am. Chem. Soc. 2001, 123, 5586-5587.

3 For pioneering examples see: (a) K. Hanabusa, T. Miki, Y. Taguchi, T. Koyama and H. Shirai, J. Chem. Soc., Chem. Commun. 1993, 1382-1384. (b) M. Tata, V. T. John, Y. Y. Waguespack and G. L. McPherson, J. Am. Chem. Soc. 1994, 116, 9464-9470.

4 (a) K. S. Partridge, D. K. Smith, G. M. Dykes and P. T. McGrail, Chem. Commun. 2001, 319-320. (b) A. R. Hirst, D. K. Smith, M. C. Feiters, H. P. M. Geurts and A. C. Wright, J. Am. Chem. Soc. 2003, 125, 9010-9011. (c) G. M. Dykes and D. K. Smith, Tetrahedron 2003, 59, 3999-4009. (d) A. R. Hirst, D. K. Smith, M. C. Feiters and H. P. M. Geurts, Langmuir 2004, 20, 7070-7077. (e) A. R. Hirst, D. K. Smith, M. C. Feiters and H. P. M. Geurts, Chem. Eur. J. 2004, in press.

5 E.g. (a) X. Luo, B. Liu and Y. Liang, Chem. Commun. 2001, 15561557. (b) N. Yamada, T. Imai and E. Koyama, Langmuir 2001, 17, 961-963. (c) S. Bhattacharya and Y. Krishnan-Ghosh, Chem. Commun. 2001, 185-186. (d) L. A. Estroff, J. S. Huang and A. D. Hamilton, Chem. Commun. 2003, 2958-2959. (e) M. Suzuki, M. Yumoto, M. Kimura, H. Shirai and K. Hanabusa, Helv. Chim. Acta 2004, 87, 1-10.

6 We have recently published a discussion of dendritic effects on gelphase materials and proposed that they rely on a subtle balance between additional favourable interactions at higher generation (such as hydrogen bonds) and unfavourable features such as greater steric repulsion and entropic cost of network formation when using more complex dendritic building blocks. A. R. Hirst and D. K. Smith, Org. Biomol. Chem. 2004, DOI: 10.1039/b409272d.

7 We have previously struggled to get SEM images of higher generation one-component dendritic gels - we postulated a flattened morphology which was difficult to image. C. S. Love, A. R. Hirst, 
V. Chechik, D. K. Smith, I. Ashworth and C. Brennan, Langmuir 2004, 20, 6580-6585.

8 Circular dichroism was not performed on dendron 1 in cyclohexane owing to its poor solubility and the formation of cloudy/opaque gels. 
